\title{
HETEROGENEOUS CORRELATION MAP BETWEEN ESTIMATED ENSO AND IOD FROM ERA5 AND HOTSPOT IN INDONESIA
}

\author{
Sri Nurdiati ${ }^{a}$, Fahren Bukhari ${ }^{a}$, Muhammad Tito Julianto ${ }^{a}$, Mohamad Khoirun Najib ${ }^{a}$, Nuzhatun \\ Nazria $^{a}$
}

${ }^{a}$ Department of Mathematics, Faculty of Mathematics and Natural Sciences, IPB University, Bogor 16680, Indonesia

\section{ARTICLE INFO}

\section{Article history:}

Received: 30 April 2021

Accepted: 13 July 2021

Published: 20 July 2021

\section{Keywords:}

El Nino-Southern Oscillation; Heterogeneous Correlation Map; Hotspot; Indian Ocean Dipole; Singular Value Decomposition

\section{Corresponding author:}

Sri Nurdiati

IPB University, Bogor, Indonesia

Email: nurdiati@apps.ipb.ac.id

\begin{abstract}
El Nino-Southern Oscillation (ENSO) and Indian Ocean Dipole (IOD) can reduce the amount of rainfall in Indonesia. The previous study found that ENSO and IOD derived from the OISST dataset have an association with hotspots in Indonesia, especially in southern Sumatra dan Kalimantan. But the correlation results are still too small, and the correlation strength between regions has not been analyzed. Therefore, this study quantifies the association of the estimated ENSO and IOD derived from the ERA5 dataset on hotspots in Indonesia based on a Heterogeneous Correlation Map (HCM) and analyzes the correlation strength between regions in Indonesia. We use a singular value decomposition method to quantify this HCM. Besides OISST, ERA5 is an estimation data often used for weather forecast analysis. Therefore, this study quantifies the association of the estimated ENSO and IOD derived from the ERA5 dataset on hotspots in Indonesia based on a Heterogeneous Correlation Map (HCM) and analyzes the correlation strength between regions in Indonesia. Based on variance explained and correlation strength, the hotspot in Indonesia is more sensitive to ENSO and IOD derived from ERA5 than OISST. Consequently, the ERA5 data more useful to statistical analysis that requiring a substantial correlation.
\end{abstract}

Copyright (C) 2021 The Authors This open-access article is distributed under a Creative Commons Attribution (CC-BY) 4.0 International license

\section{Introduction}

Indonesia is a tropical country with rainy and dry seasons (Aldrian, 2008). Generally, Indonesia's rainy and dry seasons occur during the west and east Asia-Australian monsoon, respectively. Even though the seasons occur periodically, the season's length can vary each year, such as the longer the dry season (Ashok et al., 2003). One of the factors that cause seasonal shifts in Indonesia is global climate phenomena such as the Indian Ocean Dipole (IOD) and the E1 Nino-Southern Oscillation (ENSO) (Saji et al., 1999).

ENSO and IOD have a high impact on reducing rainfall in Indonesia (Nur'utami and Hidayat, 2016). ENSO and IOD can be indicated using Nino3.4 and Dipole Mode Index, respectively. There are many negative impacts from the reduced rainfall, such as drought, crop failure, and forest fires. Forest fires are a disaster that often occurs in Indonesia. Forest fires can reduce air quality so that many people are infected Acute Respiratory Distress Syndrome (ARDS) (Saharjo and Ramadhania, 2019; Perwitasari and Sukana, 2012). The forest fire indicator that is generally used is a hotspot (Ikhwan, 2016).

The previous study found that anomalies SST in the Nino3.4 region associated with hotspots in South, East, and Central Kalimantan Provinces whereas anomalies SST in the DMI region associated with hotspots in Lampung, South Sumatera, West, South, and Central Kalimantan Provinces (Dafri et al., 2021). That study uses SST data derived from the OISST dataset and heterogeneous correlation map based on singular value decomposition to describe the correlation of hotspots with ENSO variance and IOD variance on spatial patterns. However, the correlation results of that study are still too small, and the correlation strength between regions in Indonesia has not been analyzed. 
Besides OISST, ECMWF Reanalysis Fifth Generation (ERA5) is an estimation data often used for weather forecast analysis. The European Centre for Medium-Range Weather Forecast (ECMWF) provides global forecasts, climate reanalysis, and specific datasets designed to meet different user requirements. ECWMF is often used as reference data on weather forecasts, especially for member countries, including Indonesia, and is often used to analyze weather and climate forecasting (Najib and Nurdiati, 2021; Nurdiati, Sopaheluwakan and Najib, 2019). Reanalysis combines model data with observations from across the world into a globally complete and consistent dataset using the laws of physics (Hersbach et al., 2019a). We use ERA5 datasets since ERA5 has many innovative features. These include hourly output throughout and an uncertainty estimate. The uncertainty information is obtained from a 10-member ensemble of data assimilations with 3-hourly output (Hersbach et al., 2019b).

The higher correlation strength makes the data more useful to statistical analysis that requiring a substantial correlation value to be used properly (Nurdiati, Sopaheluwakan, and Septiawan, 2021a). Therefore, this study quantifies the association of the estimated ENSO and IOD derived from the ERA5 dataset on hotspots in Indonesia based on a Heterogeneous Correlation Map (HCM) and analyzes the correlation strength between regions in Indonesia. The results are expected to increase knowledge about the association between sea surface temperature datasets, especially in Nino3.4 and IOD against hotspots in Indonesia. Also, to find out which dataset has the highest association with hotspots. In the future, this can be considered in selecting a dataset to develop a hotspot prediction model.

\section{Materials and Method}

\subsection{Study area and datasets}

The hotspot data obtained from the National Institute of Aeronautics and Space of Indonesia (LAPAN) was derived from the Moderate Resolution Imaging Spectroradiometer (MODIS) sensors of the Terra and Aqua Satellites on a spatial resolution of $0.25^{\circ} \times 0.25^{\circ}$ from 2001-2020 (Nurdiati et al., 2021b). The hotspot data cover the Asia-Pacific area, but this study only uses Indonesian territory. Meanwhile, estimated ENSO and IOD data were obtained from ECMWF Reanalysis Fifth Generation (ERA5) that can be downloaded via cds.climate.copernicus.eu.

\subsection{Heterogeneous correlation map based on singular value decomposition}

Let $P$ and $S$ be spatial $\times$ temporal 2-dimensional matrices of the hotspot and the anomaly of sea surface temperature in Nino3.4 or IOD data, respectively. Using singular value decomposition (SVD), the dimension of cross-correlation matrix $P S^{T}$ can be decomposed by

$P S^{T}=U \Sigma V^{T}$

$U$ and $V$ are singular vectors of $P$ and $S$, respectively, and $\Sigma$ is a diagonal matrix containing singular values $\sigma_{i}$ of cross-correlation matrix $P S^{T}$ (Dafri et al., 2021). The singular value decomposition is a powerful technique in many matrix computations and analyses. Using the SVD of the matrix in computation, rather than the original matrix, has the advantage of being more robust to numerical errors (Leach, 1995).

Temporal Analysis was performed using the expansion coefficients of the $P$ and $S$ matrices. The expansion coefficient of the $P$ and $S$ matrices was obtained from $U^{T} P$ and $V^{T} S$, respectively, and given by $E_{1}=U^{T} P$

$E_{2}=V^{T} S$

$E_{1}$ and $E_{2}$ are temporal patterns of hotspot and ENSO or IOD, respectively (Björnsson and Venegas, 1997). Spatial Analysis used the Heterogeneous Correlation Map (HCM) to describe the correlation of hotspots in Indonesia with varying values of the ENSO or IOD. The HCM of hotspots is obtained from the correlation between the expansion coefficient of ENSO or IOD and hotspots in Indonesia, given by $r\left(E_{2}, P\right)$ (Björnsson and Venegas, 1997).

This study uses Pearson correlation to calculate the association between hotspot and ENSO nor hotspot and IOD (Benesty et al., 2009). In addition, several time lags were used to consider the delay of ENSO and IOD effects on hotspots in Indonesia, namely a lag of 0 to 4 months.

This study only analyzes some of the main dominant spatial and temporal patterns of SVD results or called modes. Each mode is obtained from each vector of the matrices generated by the SVD process. For example, the first mode of the temporal patterns of hotspots is obtained from the first vector of the matrix $E_{1}$, the second mode is obtained from the second vector and so on. Moreover, the contribution of each mode is represented by the squares of the singular value $\left(\sigma_{i}^{2}\right)$. 

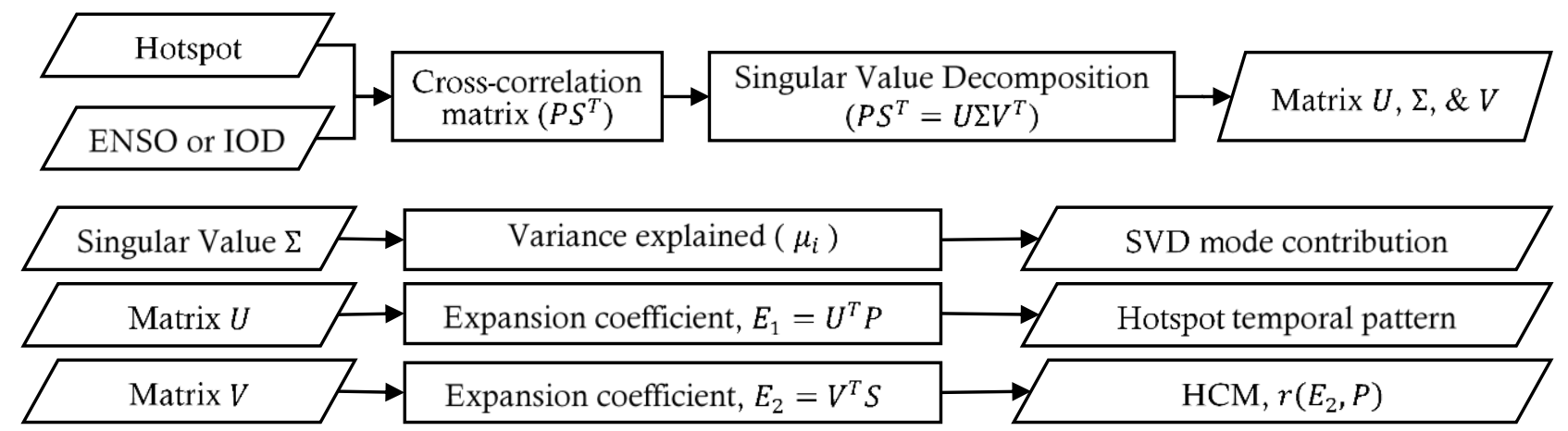

Figure 1. The flow chart process of creating the heterogeneous correlation map based on singular value decomposition between hotspot and ENSO nor hotspot and IOD

The total variance is the sum of the squares of the singular value $\sigma_{i}$. Thus, the percentage contribution of each mode $\left(\mu_{i}\right)$ derived from dividing $\sigma_{i}^{2}$ by the total variance, given by

$$
\mu_{i}=\frac{\sigma_{i}^{2}}{\sum_{i=1}^{n} \sigma_{i}^{2}}
$$

where $n$ is the number of modes given by the rank of $P S^{T}$ (Navarra and Simoncini, 2010). Figure 1 shows the process of creating the heterogeneous correlation map based on singular value decomposition between hotspot and ENSO nor hotspot and IOD.

\subsection{Boxplot analysis}

The boxplot analysis summarizes and compares the associations between hotspots and ENSO or IOD in different parts of Indonesia (Benesty et al., 2009). These areas are partitioned based on the fire characteristics of the area. The area includes northern Sumatra (Riau and Jambi Provinces, A1), southern Sumatra (Lampung and South Sumatra Provinces, A2), Kalimantan (A3), and Papua (Merauke, A4). For example, northern Sumatra has dry seasons twice a year, which causes fires to occur at the beginning and middle of the year (Septiawan et al., 2019). Two provinces of South Sumatra and Central Kalimantan with the highest hotspots counts also have the most increased peatland fire occurrence $(19,403$ and 20,324, respectively) and the highest fire densities (which is fire count relative to the area) in peatland areas among all the provinces in 2015 (Miettinen et al., 2017). Previous research found that IOD had more impact in southern Sumatra, while ENSO had more effect in Kalimantan (Nurdiati et al., 2021b). In addition, Papua is an area where forest fires often occur after Sumatra and Kalimantan, especially Merauke (Nurdiati et al., 2019). The boxplot of each area represents the distribution of the associations between hotspots and ENSO or IOD at each point in the area. The area partitioning mentioned above is shown in Figure 2.

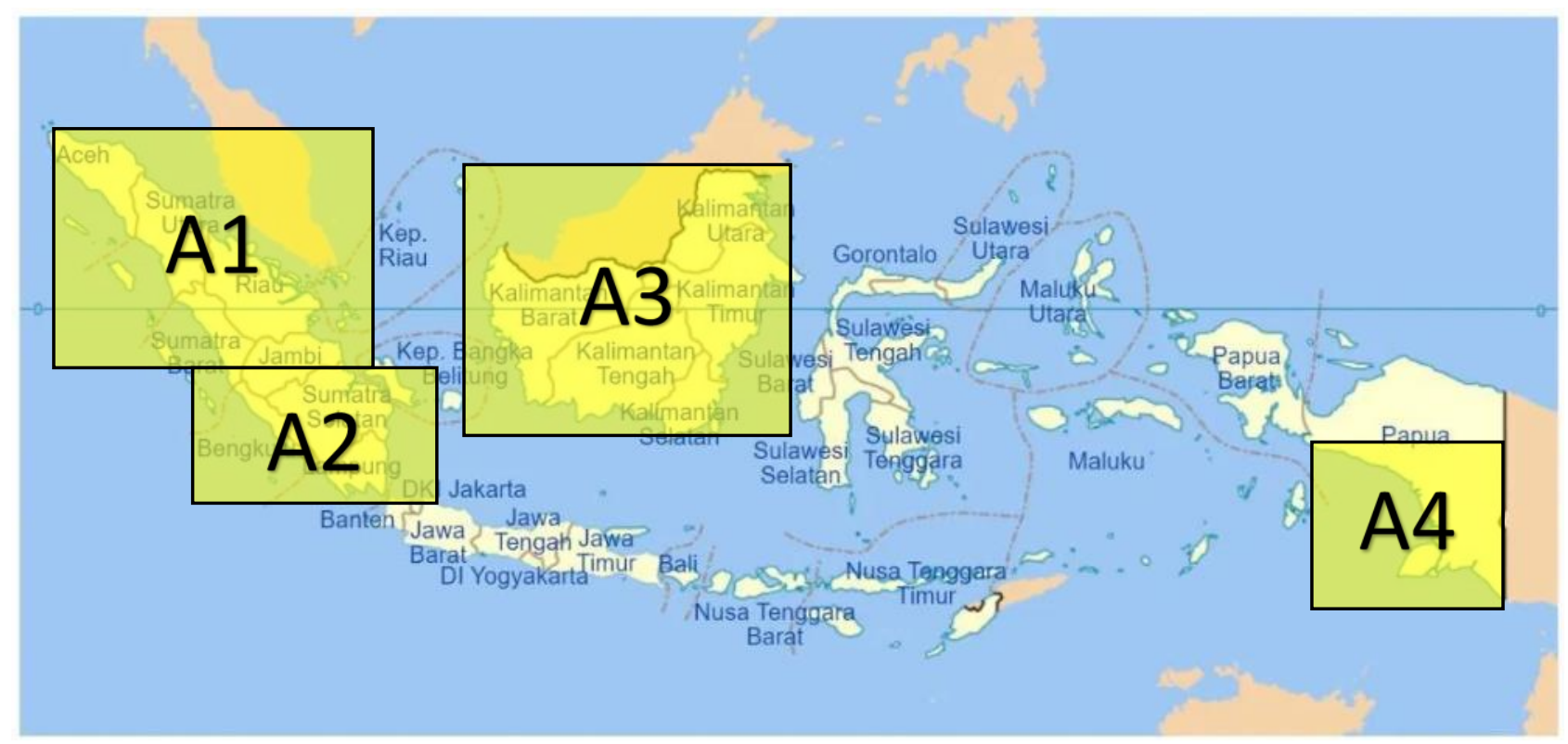

Figure 2. Partition of the area based on the fire characteristic 

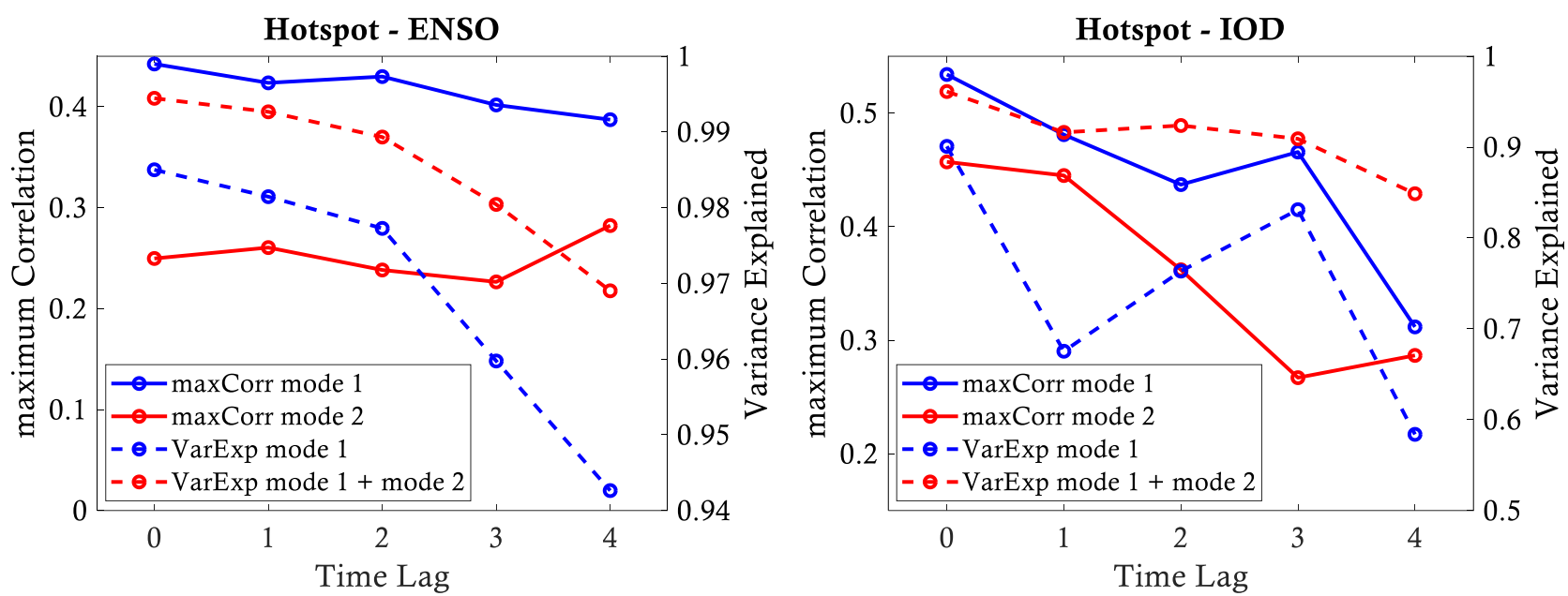

Figure 3. The maximum correlation of the heterogeneous correlation map at the time lag of $0-4$ months and the variance explained in the first and second modes between hotspot and ENSO nor IOD.

\section{Results and Discussions}

\subsection{Heterogeneous correlation map between hotspot and ENSO nor hotspot and IOD}

Of the several time lags tried, zero lag gave the best results on the heterogeneous correlation map between hotspot and ENSO nor hotspot and IOD. Figure 3 shows the maximum correlation of the heterogeneous correlation map between hotspot and ENSO nor hotspot and IOD at the time lag of 0-4 months also the variance explained in the first and second modes.

Variance explained indicates how much the contribution of a single-mode can explain the entire data. Thus, the total variance explained is $100 \%$ if all the modes are added together (in this case there are 228 modes, obtained from the rank matrix of $P S^{T}$ ). From Figure 3, both variance explains and maximum correlation occurs at zero lag. The singular value decomposition result on the cross-correlation matrix between hotspots and ENSO nor hotspot and IOD at zero lag is given in Table 1.

Both ENSO and IOD, mode 1 has the highest variance explained with more than $90 \%$, which means that mode 1 can represent more than $90 \%$ of the variability between hotspot and ENSO nor hotspot and IOD. Consequently, 90\% of information of the original matrix data can be explained using mode 1 . Therefore, the analysis is focused on mode 1, while modes 2 and 3 between hotspot and IOD are analyzed as additional information. Thus, the total variance analyzed was more than $98 \%$. The heterogeneous correlation map of hotspots in the first mode with ENSO and IOD is shown in Figure 4.

The first mode singular value decomposition between hotspot-ENSO and hotspot-IOD has variance explained $98.15 \%$ and $90.09 \%$, respectively. Figure 4 found that ENSO has associations with hotspots in South Sumatra, Central, South, and East Kalimantan, and Papua Provinces. Slightly different, IOD has associations with hotspots in a larger area. South Sumatra, Central, South, and East Kalimantan, and Papua Provinces, IOD also has associations with hotspots in Jambi, Lampung, and West Kalimantan Provinces. Similar to that discussed by Dafri et al. (2021). The highest spatial correlation between hotspot and ENSO is 0.442 in Merauke.

Meanwhile, the highest spatial correlation between hotspot and IOD is 0.534 in South Sumatra Province. From the temporal pattern, the first mode pattern is very similar between hotspot-ENSO and hotspot-IOD. Both time series represent the great fires of 2015 when the strong El Nino and positive IOD

Table 1. The first five modes singular value decomposition result on the cross-correlation matrix between hotspots and ENSO nor hotspot and IOD

\begin{tabular}{lllllll}
\hline \multirow{2}{*}{ Modes } & \multicolumn{2}{l}{ Hotspot-ENSO } & \multicolumn{5}{l}{ Hotspot-IOD } \\
\cline { 2 - 7 } & $\begin{array}{l}\text { Singular } \\
\text { Value }\end{array}$ & $\begin{array}{l}\text { Variance } \\
\text { Explained }\end{array}$ & Cumulative & $\begin{array}{l}\text { Singular } \\
\text { Value }\end{array}$ & $\begin{array}{l}\text { Variance } \\
\text { Explained }\end{array}$ & \multirow{2}{*}{ Cumulative } \\
\hline 1 & 1176696.3 & $98.50 \%$ & $98.50 \%$ & 1392995.1 & $90.09 \%$ & $90.09 \%$ \\
2 & 115218.1 & $0.94 \%$ & $99.45 \%$ & 360512.1 & $6.03 \%$ & $96.12 \%$ \\
3 & 44260.4 & $0.14 \%$ & $99.58 \%$ & 240089.1 & $2.68 \%$ & $98.80 \%$ \\
4 & 40814.3 & $0.12 \%$ & $99.70 \%$ & 91398.2 & $0.39 \%$ & $99.18 \%$ \\
\hline
\end{tabular}



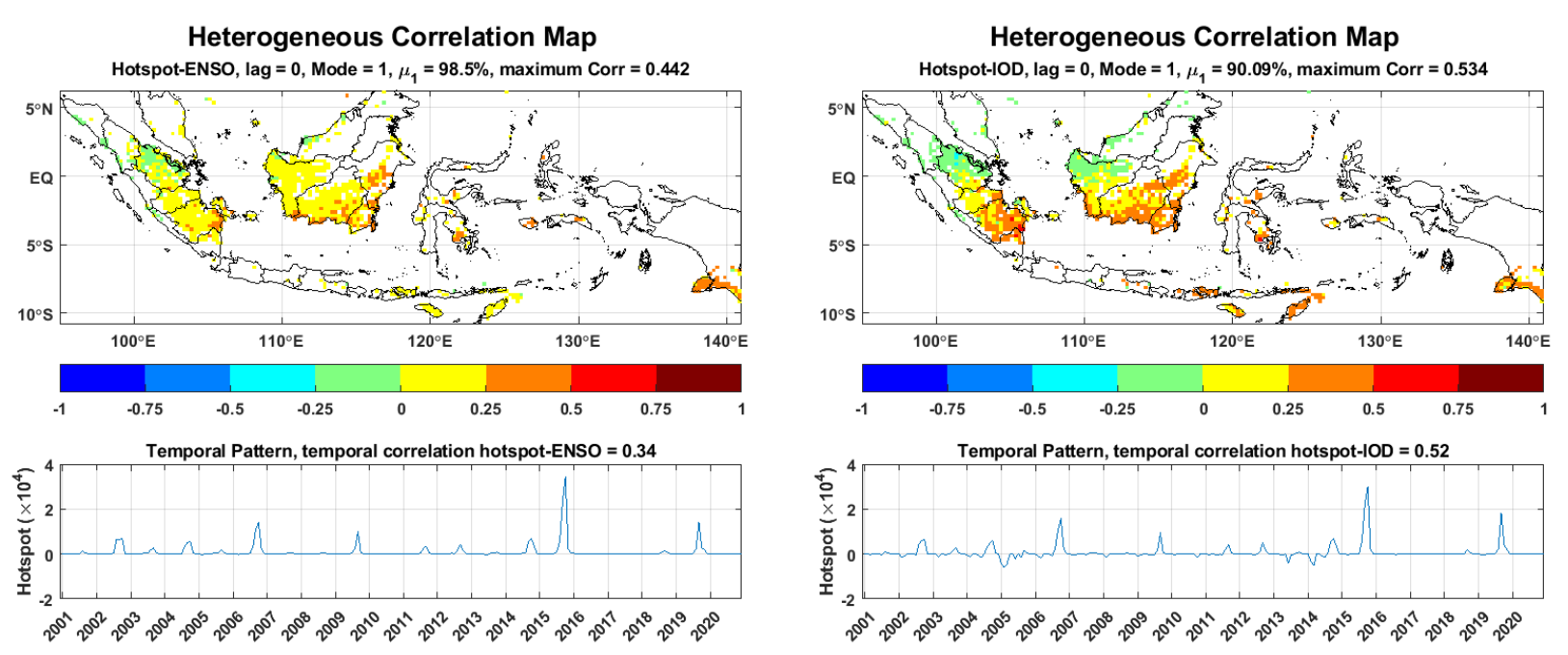

Figure 4. The heterogeneous correlation map and temporal pattern of hotspots in the first mode singular value decomposition with ENSO (left) and IOD (right).

occur simultaneously. Although not as extreme as 2015, El Nino and positive IOD also occurred simultaneously in 2002, 2006, 2009, and 2014 (Fanin and Van Der Werf, 2017). From the map dan temporal pattern, IOD amplified El Nino's influence on hotspots in Kalimantan, while in southern Sumatra, IOD triggered hotspots in areas not affected by E1 Nino (Pan et al., 2018; Kurniadi et al., 2021) so that the fire area was getting bigger. Moreover, the temporal hotspot-IOD pattern cannot describe the extreme positive IOD in 2019 but will be explained in mode 2.

Compared to OISST (Dafri et al., 2021), ERA5 has associations with hotspots in a wider area in the first mode with a similar temporal pattern, indicated by a wider red area $(\rho>0.25)$. From the correlation, the temporal pattern correlation for hotspot-ENSO and hotspot-IOD from ERA5 is 0.34 and 0.52 , respectively, higher than OISST at 0.291 and 0.338 , respectively. The variance explained in the hotspotENSO and hotspot-IOD first mode is also higher than OISST, which has variance explained $79.69 \%$ and $48.68 \%$, respectively.

Modes 2 and 3 of the singular value decompositions between hotspot and IOD provide results that explain the extreme events of IOD and forest fires at the beginning of the year in Riau Province. The variance explained for each mode is $6.03 \%$ and $2.68 \%$, respectively. The heterogeneous correlation map and temporal pattern of hotspots with IOD in the second and third modes are shown in Figure 5.

From the second singular value decomposition mode, we found that IOD has associations with hotspots in South Sumatra and West Kalimantan Provinces when the IOD is positive such as in 2002, 2015, and 2019. The highest spatial correlation between hotspot and IOD in the second mode is 0.457 in West Kalimantan Province. Hotspot on West Kalimantan Province is located in plantation forestry and
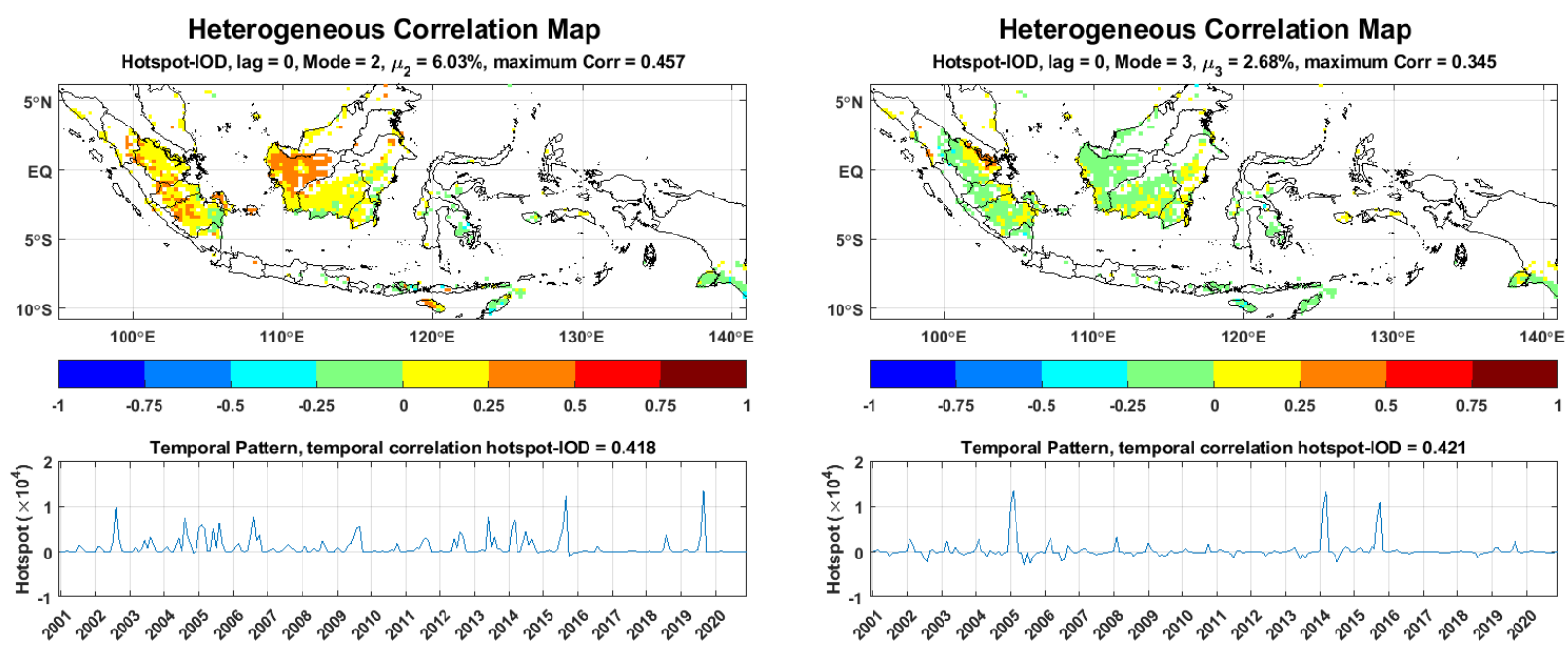

Figure 5. The heterogeneous correlation map and temporal pattern of hotspots with IOD in the second mode (left) and third mode (right). 
Table 2. The number of grids with a correlation $\rho>0.35$ and the maximum correlation from HCM results in northern Sumatra (A1), southern Sumatra (A2), Kalimantan (A3), and Papua (A4)

\begin{tabular}{|c|c|c|c|c|c|c|c|c|}
\hline \multirow{2}{*}{$\begin{array}{l}\text { HCM } \\
\text { hotspot with }\end{array}$} & \multicolumn{4}{|c|}{ Number of grids with $\rho>0.35$} & \multicolumn{4}{|c|}{ Maximum correlation } \\
\hline & A1 & $\mathrm{A} 2$ & A3 & A4 & A1 & A2 & A3 & A4 \\
\hline ENSO & 0 & 0 & 3 & 11 & 0.257 & 0.337 & 0.407 & 0.442 \\
\hline IOD 1 & 2 & 51 & 43 & 11 & 0.370 & 0.524 & 0.486 & 0.457 \\
\hline IOD 2 & 3 & 7 & 16 & 0 & 0.413 & 0.457 & 0.411 & 0.064 \\
\hline IOD 3 & 0 & 0 & 0 & 0 & 0.345 & 0.097 & 0.244 & 0.110 \\
\hline
\end{tabular}

oil palm expansion (Stibig et al., 2014). Substantial portions of West Kalimantan became new and statistically significant hotspots of forest loss in 2013 and 2014 (Harris et al., 2017). Meanwhile, from the third singular value decomposition mode, we found that IOD has associations with hotspots in coastal Riau Province when fires occur at the beginning of the year. However, the temporal pattern shows that mode 3 still explains hotspot occurrence in the middle of the year 2015. The highest spatial correlation between hotspot and IOD in the third mode is 0.345 in Riau Province. Riau does have its fire characteristics. Due to its location on the equator, Riau has two dry seasons, so fires often occur at the beginning and middle of the year. In addition, because peatlands cover the location, a previous study revealed that in periods 2001-2014, the highest density of hotspot found in Riau province and South Sumatera province, especially in Dumai, Bengkalis, Rokan Hilir, and Ogan Komering Ilir district (Kirana et al., 2016).

The second mode of hotspot-ENSO dan fourth mode of hotspot-IOD has very small variance explained. The maximum of the heterogeneous correlation maps is no more than 0.25 so that the results were neglected. Compared to OISST, hotspots are more sensitive to ENSO and IOD estimates derived from ERA5. With a higher variance explained, ERA5 can explain the variability of joint pattern between hotspot and ENSO nor hotspot and IOD better than OISST.

\subsection{Boxplot analysis}

Table 2 shows the number of grids with a correlation $\rho>0.35$ and the maximum correlation from HCM results, while Figure 6 shows the HCM boxplot of each partitioned area mentioned above. In the first mode, which is the main pattern of hotspot-ENSO and hotspot-IOD, the number of grids with a correlation $\rho>0.35$ corresponds to the maximum spatial correlation from HCM results in each area. Table 2 and Figure 6 show that hotspots in Kalimantan are more sensitive to ENSO conditions than hotspots in southern Sumatra. However, the most sensitive area to ENSO is Papua. Meanwhile, hotspots in northern Sumatra (Riau) have a very small (even not) association with ENSO. Otherwise, hotspots in southern Sumatra are more sensitive to IOD conditions than hotspots in Kalimantan. Moreover, hotspots in Papua are more sensitive to IOD conditions than hotspots in Kalimantan but not as sensitive as hotspots in southern Sumatra. Thus, like ENSO, hotspots in northern Sumatra (Riau) have a very small (even not) association with IOD. The same thing is also explained by Nurdiati et al. (2021).

In the second mode of hotspot-IOD heterogeneous correlation maps, Kalimantan (especially in West Kalimantan Province that is shown by the red area in HCM) has more area than Sumatra with a
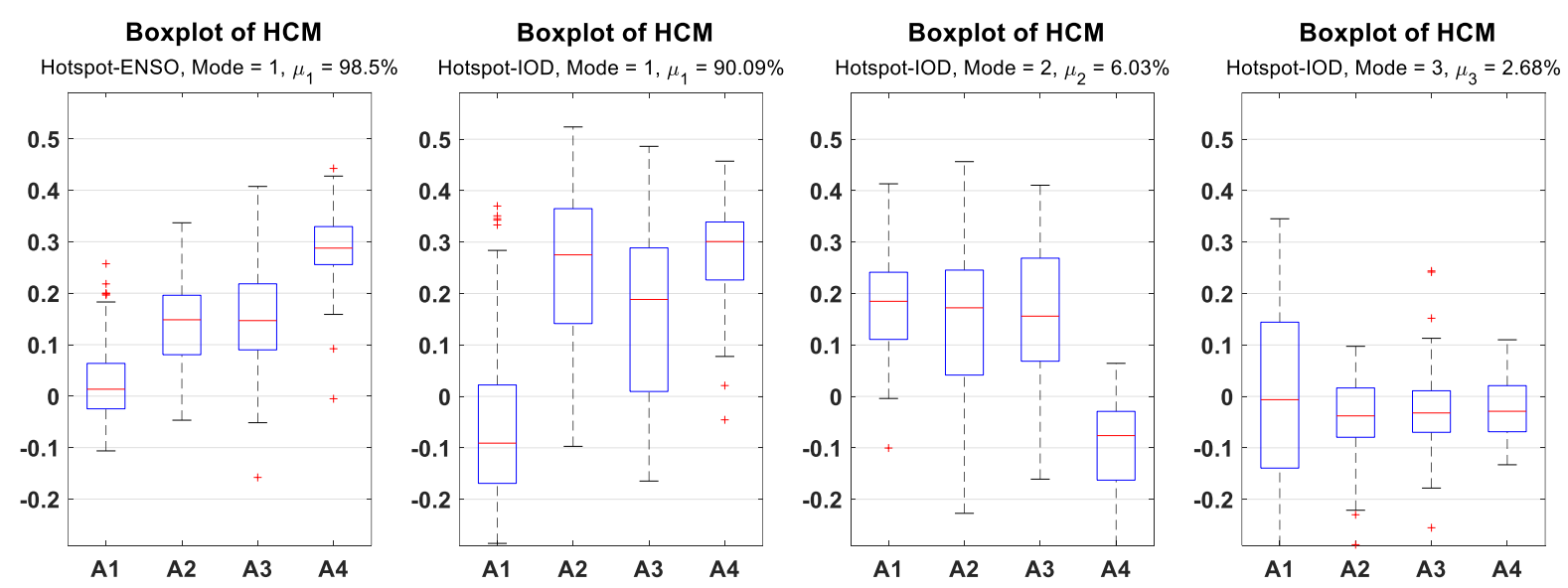

Figure 6. The boxplot of heterogeneous correlation map of hotspot-ENSO and hotspot-IOD in northern Sumatra (A1), southern Sumatra (A2), Kalimantan (A3), and Papua (A4) 
correlation of more than 0.35 . Still, the strength of the correlation is greater in southern Sumatra. Thus, the results are still in line with the results in the first mode. Furthermore, there has been an increase in associations between IOD and hotspots in northern Sumatra, but the resulting associations are still smaller than hotspots in southern Sumatra and Kalimantan. Meanwhile, in Papua, there is no indication of an association. In the second mode of hotspot-IOD heterogeneous correlation maps, although HCM shows an association between IOD and hotspots in coastal Riau Province, the strength of the correlation is still smaller than the hotspots in southern Sumatra and Kalimantan in the two previous modes. As a result, there is no correlation of more than 0.35 . Moreover, in another area, there is no indication of an association.

\section{Conclusions}

Based on the results and discussions section, the heterogeneous correlation map between estimated ENSO and IOD from ERA5 and hotspot in Indonesia can describe the main spatial and temporal patterns of hotspots and ENSO nor hotspot and IOD. Furthermore, the special and unique events such as extreme positive IOD and hotspot at the beginning of the year can be explained. ENSO is more associated with hotspots in Papua and Kalimantan than in southern Sumatra from the boxplot analysis. Otherwise, IOD is more associated with hotspots in southern Sumatra than in the southern part of Kalimantan and Papua. Moreover, hotspots in northern Sumatra (Riau) have a very small (even not) association with ENSO nor IOD. Based on variance explained and correlation strength, the hotspot in Indonesia is more sensitive to ENSO and IOD derived from ERA5 than OISST. Consequently, the ERA5 data is more useful to statistical analysis that requiring a substantial correlation.

\section{Acknowledgments}

The authors would like to thank the Department of Mathematics, IPB University, and the Meteorological, Climatological, and Geophysical Agency of Indonesia for their support throughout this research.

\section{References}

Aldrian, E., 2008. Meteorologi Laut Indonesia. Jakarta: Badan Meteorologi dan Geofisika.

Ashok, K., Guan, Z. and Yamagata, T., 2003. A look at the relationship between the ENSO and the Indian Ocean Dipole. Journal of the Meteorological Society of Japan, 81(1), pp.41-56.

Benesty, J., Chen, J., Huang, Y. and Cohen, I., 2009. Pearson correlation coefficient. In: Noise reduction in speech processing. Berlin, Heidelberg: Springer.pp.1-4.

Björnsson, H. and Venegas, S.A., 1997. A Manual for EOF and SVD Analysis of Climatic Data. CCGCR Report, 97, p.52.

Dafri, M., Nurdiati, S. and Sopaheluwakan, A., 2021. Quantifying ENSO and IOD impact to hotspot in Indonesia based on Heterogeneous Correlation Map (HCM). Journal of Physics: Conference Series, 1896, p.012150.

Fanin, T. and Van Der Werf, G.R., 2017. Precipitation-fire linkages in Indonesia (1997-2015). Biogeosciences, 14(18), pp.3995-4008.

Harris, N.L., Goldman, E., Gabris, C., Nordling, J., Minnemeyer, S., Ansari, S., Lippmann, M., Bennett, L., Raad, M., Hansen, M. and Potapov, P., 2017. Using spatial statistics to identify emerging hot spots of forest loss. Environmental Research Letters, 12(2).

Hersbach, H., Bell, B., Berrisford, P., Biavati, G., Horányi, A., Muñoz Sabater, J., Nicolas, J., Peubey, C., Radu, R., Rozum, I., Schepers, D., Simmons, A., Soci, C., Dee, D. and Thépaut, J.-N., 2019a. ERA5 monthly averaged data on single levels from 1979 to present. Copernicus Climate Change Service (C3S) Climate Data Store (CDS).

Hersbach, H., Bell, B., Berrisford, P., Horányi, A., Sabater, J.M., Nicolas, J., Radu, R., Schepers, D., Simmons, A., Soci, C. and Dee, D., 2019b. Global reanalysis: goodbye ERA-Interim, hello ERA5. ECMWF Newsletter, (159), pp.17-24.

Ikhwan, M., 2016. Pemetaan Daerah Rawan Kebakaran Hutan Dan Lahan Di Kabupaten Rokan Hilir. Wahana Forestra: Jurnal Kehutanan, 11(1), pp.57-66.

Kirana, A.P., Sitanggang, I.S. and Syaufina, L., 2016. Hotspot Pattern Distribution in Peat Land Area in Sumatera Based on Spatio Temporal Clustering. Procedia Environmental Sciences, 33, pp.635-645.

Kurniadi, A., Weller, E., Min, S.K. and Seong, M.G., 2021. Independent ENSO and IOD impacts on 
rainfall extremes over Indonesia. International Journal of Climatology.

Leach, S., 1995. Singular value decomposition-a primer. Providence, RI, USA.

Miettinen, J., Shi, C. and Liew, S.C., 2017. Fire Distribution in Peninsular Malaysia, Sumatra and Borneo in 2015 with Special Emphasis on Peatland Fires. Environmental Management, 60(4), pp.747-757.

Najib, M.K. and Nurdiati, S., 2021. Koreksi Bias Statistik Pada Data Prediksi Suhu Permukaan Air Laut Di Wilayah Indian Ocean Dipole Barat Dan Timur. Jambura Geoscience Review, 3(1), pp.9-17.

Navarra, A. and Simoncini, V., 2010. A guide to empirical orthogonal functions for climate data analysis. Springer Science \& Business Media.

Nur'utami, M.N. and Hidayat, R., 2016. Influences of IOD and ENSO to Indonesian Rainfall Variability: Role of Atmosphere-ocean Interaction in the Indo-pacific Sector. In: Procedia Environmental Sciences. pp.196-203.

Nurdiati, S., Sopaheluwakan, A., Agustina, A. and Septiawan, P., 2019. Multivariate analysis on Indonesian forest fire using combined empirical orthogonal function and covariance matrices. In: IOP Conference Series: Earth and Environmental Science. IOP Publishing.p.012048.

Nurdiati, S., Sopaheluwakan, A. and Najib, M.K., 2019. Statistical Bias Correction for Predictions of Indian Ocean Dipole Index With Quantile Mapping Approach. In: International MIPAnet Conference on Science and Mathematics (IMC-SciMath), Medan.

Nurdiati, S., Sopaheluwakan, A. and Septiawan, P., 2021a. Multivariate Regression Hotspot Model Using Local And Global Climate Indicators In South Sumatra. In: 2nd International Conference on Tropical Meteorology and Atmospheric Sciences.

Nurdiati, S., Sopaheluwakan, A. and Septiawan, P., 2021b. Spatial and Temporal Analysis of E1 Niño Impact on Land and Forest Fire in Kalimantan and Sumatra. Agromet, 35(1), pp.1-10.

Pan, X., Chin, M., Ichoku, C.M. and Field, R.D., 2018. Connecting Indonesian Fires and Drought With the Type of El Niño and Phase of the Indian Ocean Dipole During 1979-2016. Journal of Geophysical Research: Atmospheres, 123(15), pp.7974-7988.

Perwitasari, D. and Sukana, B., 2012. Gambaran Kebakaran Hutan Dengan Kejadian Penyakit Ispa Dan Pneumonia Di Kabupaten Batang Hari, Provinsi Jambi Tahun 2008. Indonesian Journal of Health Ecology, 11(2), pp.147-157.

Saharjo, B.H. and Ramadhania, D., 2019. Hubungan antara Hotspot Dan Kebakaran Terhadap Timbulnya Penyakit Infeksi Saluran Pernapasan Akut (ISPA) di Kabupaten Kubu Raya, Kalimantan Barat. Jurnal Silvikultur Tropika, 10(3), pp.133-139.

Saji, N.H., Goswami, B.N., Vinayachandran, P.N. and Yamagata, T., 1999. A dipole mode in the tropical Indian ocean. Nature, 401(6751), pp.360-363.

Septiawan, P., Nurdiati, S. and Sopaheluwakan, A., 2019. Numerical Analysis using Empirical Orthogonal Function Based on Multivariate Singular Value Decomposition on Indonesian Forest Fire Signal. IOP Conference Series: Earth and Environmental Science, 303(1).

Stibig, H.J., Achard, F., Carboni, S., Raši, R. and Miettinen, J., 2014. Change in tropical forest cover of Southeast Asia from 1990 to 2010. Biogeosciences, 11(2), pp.247-258. 